\title{
A Formação Matemática nos Cursos de Licenciatura em Educação do Campo*
}

\section{The Mathematical Education Bachelor's Degree in Rural Education courses}

\author{
Línlya Sachs ${ }^{* *}$ \\ Henrique Rizek Elias ${ }^{* * *}$
}

\begin{abstract}
Resumo
Neste artigo buscamos elucidar qual o lugar da Matemática em oito cursos de Licenciatura em Educação do Campo com habilitação em Matemática, a partir de seus projetos político-pedagógicos. Voltamos nossos olhares para três itens desses projetos: os objetivos do curso, o perfil esperado do egresso e as ementas dos componentes curriculares. Tomando Moreira e David (2010) e Fiorentini e Oliveira (2013) como referenciais teóricos da formação matemática do professor de Matemática e à luz da Análise Textual Discursiva, de Moraes e Galiazzi (2011), como método de análise, percebemos que, de um modo geral, a Matemática que tem sido priorizada nesses cursos é a chamada Acadêmica, que o lugar da Matemática é central e, ainda, concluímos que, na maioria dos casos, as disciplinas de conteúdo matemático vêm dissociadas do contexto social, das disciplinas didáticopedagógicas e da prática do professor.
\end{abstract}

Palavras-chave: Educação do Campo. Formação de Professores. Formação Matemática.

\begin{abstract}
This article tries to interpret what is the place of mathematics in eight Rural Education Bachelor's Degree courses with specialization in Mathematics, from their political-pedagogical projects. We turn our attention to three specific items in these projects: the course objectives, the expected profile of graduates, and the class curriculum components. Taking Moreira and David (2010) and Fiorentini and Oliveira (2013) as theoretical framework for the development of the mathematics teaching training and taking the Discursive Textual Analysis from Moraes and Galiazzi (2011) as the method of analysis, we realized that, overall, the type of math that has been prioritized in these courses is the Academic one, we also concluded that the place of mathematics is central and that, in most cases, the contents of mathematical disciplines are dissociated from the social context, from other didactic pedagogical disciplines, and from the teacher's practice.
\end{abstract}

Keywords: Rural Education. Teacher Education. Training of Mathematics Teachers. Mathematical Education.

\footnotetext{
"Este artigo é uma versão ampliada do artigo com o mesmo título, publicado nos anais do $4^{\circ}$ Simpósio Internacional de Pesquisa em Educação Matemática.

** Doutora em Educação Matemática pela Universidade Estadual Paulista "Júlio de Mesquita Filho" (UNESP). Professora da Universidade Tecnológica Federal do Paraná (UTFPR), Cornélio Procópio/PR, Brasil. Endereço para correspondência: Avenida Alberto Carazzai, 1640, Cornélio Procópio/PR, CEP 86300-000. Endereço eletrônico: linlyasachs@yahoo.com.br

${ }^{* * * *}$ Mestre e Doutorando em Ensino de Ciências e Educação Matemática pela Universidade Estadual de Londrina (UEL). Professor da Universidade Tecnológica Federal do Paraná (UTFPR), Londrina/PR, Brasil. Endereço para correspondência: Avenida dos Pioneiros, 3131, Londrina/PR, CEP 86036-370. Endereço eletrônico: henriquerizek@hotmail.com
} 


\section{Introdução}

Nos últimos anos, algumas políticas públicas vêm sendo realizadas no sentido de fortalecer a Educação no meio rural. Destacamos aí o Programa de Apoio à Formação Superior em Licenciatura em Educação do Campo (PROCAMPO), que tem como objetivo oferecer formação em cursos de licenciatura a professores leigos já atuantes no meio rural e a moradores e trabalhadores do campo que possam se tornar professores em escolas dessas áreas.

Uma ação importante nessa direção foi o lançamento de editais - em 2009 e em 2012 - pelo Ministério da Educação (mais especificamente, pela Secretaria de Educação Continuada, Alfabetização, Diversidade e Inclusão), convocando instituições públicas de Ensino Superior a apresentar propostas de cursos de Licenciatura em Educação do Campo, as quais teriam auxílio financeiro para sua implantação.

Como resposta a esses editais (BRASIL, 2009; BRASIL, 2012), ao todo, foram 65 instituições com propostas de cursos aprovados.

De acordo com pesquisa realizada por Barbosa (2014), no segundo semestre de 2013, 25 instituições tinham o curso de Licenciatura em Educação do Campo com habilitação em Matemática em andamento.

Diante disso, surge a necessidade de pesquisar que formação inicial tem sido oferecida por essas instituições aos futuros (ou já atuantes) professores de Matemática. Diversos aspectos podem ser analisados; um deles é olhar para qual Matemática tem sido priorizada nesses cursos de formação.

Há uma preocupação entre pesquisadores na área da Educação Matemática sobre o papel das disciplinas de conteúdo matemático na formação inicial do professor que ensina Matemática. Algumas são as pesquisas que abordam esse tema, dentre as quais destacamos Lins (2005), Fiorentini (2005), Fiorentini e Oliveira (2013) e Moreira e David (2010). Estas duas últimas serão abordadas na sequência deste trabalho.

Com as recentes ações do Ministério da Educação visando fortalecer a Educação do meio rural, entendemos que as preocupações com a formação inicial dos professores devem ser estendidas àqueles que atuarão na Educação do Campo.

Nesse sentido, o objetivo deste trabalho é analisar, a partir dos documentos oficiais de cada instituição, qual o lugar da Matemática em cursos de Licenciatura em Educação do Campo com habilitação em Matemática. Neste artigo, concentramo-nos em oito dos 25 cursos em andamento, pois, de acordo com Barbosa (2014), somente esses disponibilizaram à época 
seus projetos político-pedagógicos, suas grades curriculares e as ementas dos componentes curriculares.

\section{Licenciaturas em Educação do Campo: contexto}

O Brasil tem um histórico bastante excludente no que se refere à Educação para as pessoas que vivem em áreas rurais. Leite (1999) e INEP (2007) elencam problemas relativos a escolas rurais no país, dentre os quais estão a falta de infraestrutura, a atuação de professores sem formação ou com formação inapropriada e currículos inadequados.

No final da década de 1990, vários movimentos sociais brasileiros - em especial, o Movimento dos Trabalhadores Rurais Sem-Terra (MST) - organizaram-se para reivindicar mudanças nesse quadro, dando origem ao "Movimento Nacional de Educação do Campo".

Como resultado dessas reivindicações, o governo brasileiro criou em 2012 o Programa Nacional de Educação do Campo (PRONACAMPO), estruturado em quatro eixos: Gestão e Práticas Pedagógicas; Formação Inicial e Continuada de Professores; Educação de Jovens e Adultos e Educação Profissional; e Infraestrutura Física e Tecnológica. É no segundo eixo que se encontra o Programa de Apoio à Formação Superior em Licenciatura em Educação do Campo (PROCAMPO).

As Licenciaturas em Educação do Campo iniciaram-se, como experiências-piloto, em 2007 em quatro universidades do país. Em 2009 e em 2012, foram lançados editais convocando instituições públicas de Ensino Superior para apresentarem suas propostas de cursos, que teriam incentivo financeiro para sua execução.

Como consta no edital de 2009:

O Procampo fomentará projetos de cursos de licenciatura específicos em educação
do campo que integrem ensino, pesquisa e extensão e promovam a valorização da
educação do campo e o estudo dos temas relevantes concernentes às suas
populações. Os projetos deverão contemplar alternativas de organização escolar e
pedagógica, contribuindo para a expansão da oferta da educação básica nas
comunidades rurais e para a superação das desvantagens educacionais históricas
sofridas pelas populações do campo (BRASIL, 2009, p. 57 ).

Após enviarem suas propostas, 65 instituições tiveram seus cursos aprovados nesses editais. Desses, 25 cursos tinham a habilitação em Matemática ou em Ciências da Natureza e Matemática e estavam em funcionamento no segundo semestre de 2013. Dentre esses, Barbosa (2014) teve acesso aos projetos político-pedagógicos de oito deles, a saber, das seguintes instituições: Universidade Federal do Recôncavo da Bahia (UFRB), em Itaberaba;

\footnotetext{
${ }^{1}$ Para mais detalhes, consultar Munarim (2008).
} 
Universidade Federal do Pará (UFPA), em Abaetuba; Universidade Federal de Campina Grande (UFCG), em Sumé; Universidade Tecnológica Federal do Paraná (UTFPR), em Dois Vizinhos; Universidade Estadual do Oeste do Paraná (UNIOESTE), em Cascavel; Universidade Estadual do Centro-Oeste (UNICENTRO), em Laranjeiras do Sul; Universidade Federal de Roraima (UFRR), em Paricana; e Instituto Federal de Educação, Ciência e Tecnologia Farroupilha/RS (IFFarroupilha), em Jaguari. Analisamos esses documentos neste trabalho.

\section{A Matemática na formação do professor de Matemática}

Um tema que tem ganhado visibilidade nas discussões e pesquisas sobre formação inicial de professores de Matemática é o conhecimento matemático e, em particular, o papel da Matemática acadêmica (científica) nessa formação. Um exemplo dessa atenção foi o espaço dado ao tema no V Fórum Nacional de Licenciaturas em Matemática, realizado em dezembro de 2014 na Universidade Estadual de Londrina, por meio da palestra intitulada $O$ Conhecimento Matemático na formação do professor de Matemática².

Dentre as pesquisas realizadas recentemente, destacamos neste trabalho Moreira e David (2010) e Fiorentini e Oliveira (2013).

Moreira e David (2010) estabelecem formas distintas de conhecimento matemático: a Matemática Acadêmica e a Matemática Escolar. Para esses autores, a Matemática Científica ou Acadêmica é entendida como “(...) um corpo científico de conhecimentos, segundo a produzem e a percebem os matemáticos profissionais" (p. 20). Enquanto que a Matemática Escolar se refere ao conjunto de saberes

(...) 'validados', associados especificamente ao desenvolvimento do processo de educação escolar básica em Matemática. Com essa formulação, a Matemática Escolar inclui tanto saberes produzidos e mobilizados pelos professores de Matemática em sua ação pedagógica na sala de aula da escola, quanto resultados de pesquisas que se referem à aprendizagem e ao ensino escolar de conceitos matemáticos, técnicas, processos etc. (MOREIRA e DAVID, 2010, p. 20).

O que se tem percebido, no entanto, é que cursos de formação de professores têm priorizado a chamada Matemática Acadêmica, além de haver uma desconexão entre esse conhecimento matemático e a prática docente na Educação Básica. Por isso, os autores consideram a “[...] necessidade de um redimensionamento da formação matemática na licenciatura, de modo a equacionar melhor os papéis da Matemática Científica e da Matemática Escolar nesse processo" (MOREIRA; DAVID, 2010, p. 103).

\footnotetext{
${ }^{2}$ Palestra proferida por Dr. Vinício de Macedo Santos e Dra. Nilza Bertoni.
} 
Concordando com esse redimensionamento, Fiorentini e Oliveira (2013) afirmam que antes de se pensar a formação necessária ao professor de Matemática, deve-se “(...) analisar e discutir a prática social do educador matemático, pondo em evidência os saberes mobilizados e requeridos por essa prática" (p. 920).

Nesse sentido, os autores destacam três interpretações distintas sobre a prática social do professor de Matemática que influenciam na formação do professor e, por consequência, no lugar da Matemática nessa formação: i) A prática do professor é essencialmente prática, sendo o domínio do conhecimento do conteúdo suficiente para a formação, uma vez que o ato de ensinar aprende-se ensinando. Nesse caso, a Matemática tem papel central; ii) A prática de ensino da Matemática é tida como um campo de aplicação dos conhecimentos produzidos pela academia, sendo necessária uma formação dita "sólida", tanto em termos de conhecimento matemático, quanto das ciências educativas e de métodos de ensino da Matemática. Porém, estes últimos serviriam como um treinamento para se ensinar a Matemática acadêmica vista normalmente nos primeiros anos do curso de formação. Aqui o lugar da Matemática continua sendo central e distanciado das práticas escolares; iii) A prática pedagógica da Matemática é vista como uma prática social, o que requer uma formação que problematize e estude as múltiplas atividades profissionais do professor que ensina Matemática. E, diferentemente das duas perspectivas anteriores, “(...) a Matemática em ação do educador matemático está, sempre, situada em uma prática social concreta, na qual ganha sentido e forma/conteúdo próprios, sendo reconhecida e validada no/pelo trabalho" (FIORENTINI; OLIVEIRA, 2013, p. 922).

Assim, neste trabalho olhamos para os documentos oficiais dos oito cursos de Licenciatura em Educação do Campo com habilitação em Matemática apresentados na seção anterior a fim de verificar como tem sido (se é que ocorre) o equacionamento dos papéis da Matemática Científica e da Matemática Escolar, no sentido de Moreira e David (2010), e qual perspectiva, dentre aquelas destacadas em Fiorentini e Oliveira (2013), tem sido adotada por eles. Com isso, pretendemos atingir o objetivo desta pesquisa que é analisar qual o lugar da Matemática em cursos de Licenciatura em Educação do Campo.

\section{Procedimentos metodológicos}

Para atingir o objetivo proposto nesta pesquisa, apoiamo-nos na Análise Textual Discursiva (MORAES; GALIAZZI, 2011). Consideramos o corpus da análise os projetos político-pedagógicos dos cursos de Licenciatura em Educação do Campo, com habilitação em 
Matemática, das oito instituições citadas, que disponibilizaram esses documentos. $\mathrm{O}$ trabalho de Barbosa (2014) foi essencial para a listagem desses projetos e facilitador do nosso acesso a eles.

Moraes e Galiazzi (2011, p. 17) afirmam que, para delimitar o corpus, "seleciona-se um conjunto [de documentos] capaz de produzir resultados válidos e representativos”. Esses cursos de Licenciatura em Educação do Campo, pela sua recente implantação, ainda carecem de pesquisas acerca de sua especificidade; assim, apesar de pouco numerosa a quantidade de projetos político-pedagógicos (oito de 25 cursos) que analisamos, entendemos que sejam suficientes como um primeiro resultado sobre o tema aqui tratado.

O nosso olhar está voltado para alguns itens em especial desses projetos: os objetivos do curso, o perfil esperado do egresso e as ementas dos componentes curriculares. Com isso, pretendemos compreender o papel da Matemática no curso, considerando o que se espera de profissional ali formado.

Um próximo passo dos procedimentos metodológicos, após a constituição do corpus, é a desconstrução dos textos, permitindo-nos "novas compreensões em relação aos fenômenos investigados" (MORAES; GALIAZZI, 2011, p. 21). É nesse momento que os documentos, aparentemente estáticos, estabelecem o diálogo entre si, surgindo, assim, as categorias. Elas foram definidas a posteriori, com base naquilo que encontrarmos em comum entre esses cursos, a partir de seus projetos político-pedagógicos.

Estamos cientes de que a formação do professor depende fortemente de seus formadores, ou seja, dos professores que atuam no curso, de suas visões de mundo, de sua relação com o conhecimento e de sua forma de lidar com as situações de aula. Também, sabemos que, por diversas vezes, os documentos que regem um curso (como o projeto político-pedagógico) podem não ter sido elaborados por esses professores ou serem por eles considerados. É, então, uma limitação desta pesquisa: nosso corpus é constituído por esses documentos (somente por eles), e não pelos depoimentos desses professores ou por registros de suas aulas. De todo modo, esses são documentos oficiais e que, de alguma forma, orientam (ou deveriam orientar) as práticas pedagógicas nesses cursos.

\section{Análises}

Iniciamos nossas análises, olhando para os objetivos e para o perfil do egresso de cada curso. Percebemos que em cinco deles (IFFarroupilha, UFPA, UFRR, UFRB e UNICENTRO) há, explicitamente, a busca por estabelecer articulações entre a formação 
acadêmica e a vida no campo, isto é, esses projetos trazem a preocupação de fornecer uma formação profissional para aquele contexto específico. Isso pode ser observado, principalmente, a partir de palavras ou expressões-chave que nos indicam tal intuito nos trechos a seguir:

Assim como os saberes que dizem respeito ao fazer pedagógico e didático,
construindo uma formação acadêmica e científica articulada com os saberes
advindos do campo (INSTITUTO FEDERAL FARROUPILHA, 2012, p. 18, grifos nossos).

[...] no Curso de Licenciatura em Educação do Campo os professores formados, com as respectivas habilitações, são profissionais que: têm capacidade teóricometodológica na construção de estratégias pedagógicas pertinentes à realidade da Educação do Campo (INSTITUTO FEDERAL FARROUPILHA, 2012, p. 24, grifos nossos).

Conscientizar o futuro professor que o trabalho interdisciplinar produz conhecimento útil, portanto interligando teoria e prática, estabelecendo relação entre o conteúdo do ensino e realidade social escolar (UNIVERSIDADE FEDERAL DO PARÁ, 2009, p. 20, grifos nossos).

Os egressos deverão possuir uma sólida formação teórico-prática nas seguintes áreas do conhecimento: ciências naturais, matemática, linguagem que lhes possibilitem associar os conteúdos curriculares e os saberes da experiência à necessidade e realidade do campo (UNIVERSIDADE FEDERAL DO PARÁ, 2009, p. 21, grifos nossos).

Possibilitar o acesso ao Ensino Superior às populações do campo, com a finalidade de contribuir para a construção de conhecimentos pertinentes à Educação do Campo (UNIVERSIDADE FEDERAL DE RORAIMA, 2011, p. 16, grifos nossos).

Assim, espera-se que o Licenciado em Educação do Campo possa: [...] Respeitar e valorizar os diferentes saberes do campo, articulando com os conhecimentos científicos adquiridos na formação para a melhoria das condições educativas e sociais (UNIVERSIDADE FEDERAL DE RORAIMA, 2011, p. 19-20, grifos nossos).

Também, destacamos outros trechos que refletem para nós a defesa de uma educação específica para o campo:

Portanto, as concepções epistemológicas, juntamente com os saberes cotidianos e os saberes da docência comporão uma unidade voltadas para formação de um profissional compromissado com a prática educativa e social (UNIVERSIDADE FEDERAL DO RECÔNCAVO DA BAHIA, 2013).

Produzir materiais didático-pedagógicos para o trabalho nas escolas do campo (UNIVERSIDADE ESTADUAL DO CENTRO-OESTE, 2009).

Já nos projetos político-pedagógico das outras três instituições (UFCG, UTFPR e UNIOESTE), não encontramos, nos itens objetivos e perfil do egresso, a mesma clareza em estabelecer uma formação articulada com os saberes do campo. 
Os trechos apresentados anteriormente mostram-nos que esses cursos parecem almejar uma formação que, assim como afirmam Fiorentini e Oliveira (2013), estude e problematize a prática social concreta em que o futuro professor atuará.

A fim de verificar se essa articulação entre formação acadêmica e os saberes do campo efetiva-se ou não nas disciplinas de conteúdo matemático desses cursos, avançamos nossas análises, agora para as ementas dos componentes curriculares.

A tabela 1 abaixo apresenta o número de disciplinas de conteúdo matemático ${ }^{3}$ em cada uma das oito instituições analisadas, assim como suas cargas horárias:

Tabela 1 - Disciplinas de conteúdo matemático: quantidade e carga horária total

\begin{tabular}{c|c|c|c|c|c|c|c|c} 
Instituição & IFFarroupilha & UFCG & UFPA & UFRB & UFRR & UNICENTRO & UNIOESTE & UTFPR \\
\hline $\begin{array}{c}\text { Número de } \\
\text { disciplinas }\end{array}$ & 15 & 4 & 16 & 13 & 4 & 6 & 5 & 9 \\
\hline $\begin{array}{c}\text { Carga } \\
\text { horária } \\
\text { total }\end{array}$ & 880 & 240 & 1088 & 799 & 240 & 332 & 270 & 525
\end{tabular}

Fonte: produzida pelos autores (2015)

É notória a discrepância entre as cargas horárias destinadas às disciplinas de conteúdo matemático de alguns cursos. Uma das justificativas para essa diferença pode estar na habilitação que cada curso fornece. Por exemplo, o curso da UFCG, cuja carga horária de disciplinas de conteúdo matemático é 240, concede uma formação em Licenciatura em Educação do Campo com habilitação em Ciências Exatas e da Natureza (assim como as instituições UFRR, UNICENTRO, UNIOESTE e UTFPR), ou seja, a carga horária total do curso precisa ser distribuída entre outras disciplinas, como Física, Química e Biologia, e não apenas para a Matemática. Por outro lado, a UFPA, cuja carga horária destinada às disciplinas de conteúdo matemático é 1088, fornece uma Licenciatura em Educação do Campo com habilitação em Matemática (assim como as instituições IFFarroupilha e UFRB), isto é, o curso tem uma formação mais restrita à Matemática e, por isso, permite que se destine uma carga horária maior às disciplinas de conteúdo matemático.

Indo além dessa análise quantitativa, verificamos de que modo as ementas desses componentes curriculares são apresentadas, buscando averiguar se há alguma relação com a Matemática Escolar e entre a Matemática e os saberes do campo, como alguns projetos político-pedagógicos sugerem em seus objetivos, ou se a Matemática aparece dissociada do contexto social em que se efetivará a prática docente.

\footnotetext{
${ }^{3}$ Estamos entendendo por disciplinas de conteúdo matemático as disciplinas que em seus nomes envolvam: Fundamentos de Matemática, Matemática Básica, Cálculo, Análise Real, Geometria, Geometria Analítica, Álgebra Linear, Álgebra, Equações Diferenciais, Probabilidade e Estatística, Matemática Financeira.
} 
Diversos desses componentes curriculares apresentam em suas ementas conteúdos matemáticos que são abordados na Educação Básica, como: Matemática aplicada à vida no campo, da UNICENTRO; Elementos de Geometria Plana e Espacial, da UFRB; Tópicos de Matemática, da UTFPR; Introdução à Probabilidade e Estatística, da UFPA; e Matemática da Educação Básica I, II e III, da UFCG. Todos os cursos analisados apresentam componentes com essa característica.

Outros componentes curriculares - como Geometria, da UFRR, e Teoria dos Números, da UFPA - tratam de assuntos matemáticos que fazem parte dos currículos da Educação Básica, mas apenas com suas ementas não podemos dizer se o enfoque dado é o mesmo da Educação Básica ou se aproxima-se mais da Matemática do Ensino Superior, com estruturas axiomáticas de demonstração. Por exemplo, no componente Álgebra, do IFFarroupilha, um dos itens da ementa é "Números Inteiros: construção axiomática dos números Inteiros ou dos Naturais”, e, conforme Elias, Barbosa e Savioli (2011), é possível que esse tópico seja abordado de acordo com a Matemática elementar ou avançada. A bibliografia utilizada pode sinalizar para um dos dois, mas sem deixar isso claro.

Quando falamos em conteúdos matemáticos que são abordados na Educação Básica, não estamos nos referindo à Matemática Escolar, tal como definem Moreira e David (2010), pois não tratam de saberes produzidos ou validados pelo professor no contexto de sala de aula; são referentes à transposição didática da Matemática Acadêmica. Como afirmam os autores, a concepção de Matemática Escolar que adotam distancia-se daquela que “[...] a identifica como uma disciplina 'ensinada' na escola, para tomá-la como um conjunto de saberes associados ao exercício da profissão docente" (MOREIRA; DAVID, 2010, p. 21). Entendemos que se aproxima dessa Matemática Escolar a que se referem os autores a ementa do componente curricular Geometria Plana, Analítica e Espacial, da UFCG, que traz “Geometria plana: conceito e importância na sala de aula: semelhança de triângulos, Teorema de Tales, relações métricas no triângulo retângulo, polígonos regulares e comprimento de circunferência" (UNIVERSIDADE FEDERAL DE CAMPINA GRANDE, 2012), uma vez que faz referência à sala de aula.

Também identificamos componentes curriculares que em suas ementas apresentam relações com o contexto social em que o futuro professor poderá atuar. Na UFPA, temos a disciplina Geometria Plana e Espaço Agrário, que traz em sua ementa "O papel da interdependência no desenvolvimento histórico da Geometria no campo. A circunferência no campo. Entes geométricos no contexto do campo" (UNIVERSIDADE FEDERAL DO PARÁ, 
2009, p. 95); na UNIOESTE, a componente curricular Geometria, Ótica e Percepção do Espaço tem em sua ementa:

\begin{abstract}
Geometria: desenho e marcenaria; [...] A Geometria e os principais instrumentos óticos usados no campo; Os conceitos de comprimento, área e volume e métodos para sua medição; Astronomia, Cosmologia, Cartografia e Trigonometria: olhando para o céu e para a Terra. (UNIVERSIDADE ESTADUAL DO OESTE DO PARANÁ, 2013, p. 76).
\end{abstract}

Essa mesma instituição tem a disciplina Educação Financeira, que trata, entre outros temas, de "Métodos para pagamento de dívidas; Análise crítica do Pronaf e do sistema bancário brasileiro" (UNIVERSIDADE ESTADUAL DO OESTE DO PARANÁ, 2013, p. $88)$.

Todas essas três disciplinas apresentadas têm, em nosso entendimento, alguma relação explícita com a prática social do educador matemático, tal como sugerem Fiorentini e Oliveira (2013).

Outros cursos tentam fazer o mesmo, mas de forma não tão clara. O curso da UFRB, por exemplo, traz o mesmo texto em dez disciplinas de conteúdo matemático: “Aplicações contextualizadas na realidade do campo". Consideramos essa uma tentativa pouco esclarecedora de articular os conteúdos matemáticos à realidade camponesa. No caso da UNICENTRO, há cinco disciplinas cujos nomes sugerem essa articulação, mas quando olhamos suas ementas encontramos apenas conteúdos matemáticos descontextualizados. Por exemplo, a ementa da disciplina Cálculo Diferencial e Integral Aplicado à vida no campo é "Funções. Limites. Derivadas. Integrais". O mesmo ocorre com a disciplina Cálculo Integral e a vida no campo, da UNIOESTE. Ainda, na UFRR, a disciplina Geometria traz em sua ementa "Resolução de problema prático do cotidiano através da geometria plana, espacial e analítica”, que, apesar de estabelecer uma relação com o cotidiano, não se refere explicitamente ao contexto camponês.

Já os outros três cursos não citados (IFFarroupilha, UFCG e UTFPR) não fazem referência alguma com a vida no campo em suas disciplinas de conteúdo matemático.

Há, ainda, componentes curriculares com conteúdos matemáticos próprios do Ensino Superior - ou, em outros termos, da Matemática Acadêmica (MOREIRA; DAVID, 2010). São exemplos: Álgebra I, da UFPA, que tem como ementa "Introdução à teoria de grupos, de anéis, de corpos. Tópicos da história da álgebra"; Introdução à análise real, da UTFPR, cuja ementa é "Conjunto dos números naturais; Conjuntos finitos, infinitos, enumeráveis e nãoenumeráveis; corpo dos números reais ordenados e completos"; e Cálculo $C$, da UFRB, com ementa "Integral de linhas. Teorema de Green. Equações diferenciais ordinárias. Aplicações 
contextualizadas na realidade do campo. Elaboração do Plano de Estudo para o Tempo Comunidade. Seminário Integrador”.

Alguns cursos apresentam, em suas grades curriculares, considerável carga horária destinada a esse tipo de conteúdo. Na UFPA, por exemplo, são 11 disciplinas com esse viés (sendo que uma delas - Teoria dos Números -, dependendo do enfoque, pode abordar temas da Educação Básica, como dissemos anteriormente).

Sobre a formação matemática, privilegiando a Matemática Acadêmica, entendemos que ela não deve estar dissociada da prática social do professor. Nesse mesmo sentido, afirmam Fiorentini e Oliveira (2013, p. 935):

São importantes os conteúdos da matemática superior que compõem as disciplinas de formação matemática da licenciatura, pois amplia-se, assim, a visão dos futuros professores acerca da matemática como campo de conhecimento. Mas, é necessário adotarmos posturas que apontem para uma visão mais integradora do curso, sem deixar de aprofundar, numa perspectiva multirrelacional, epistemológica e históricocultural, o conteúdo específico.

Essa crítica aplica-se, também, a cursos de Licenciatura em Matemática que dedicam grande parte de sua carga horária à Matemática Acadêmica sem estabelecer relações com a prática profissional do futuro professor.

Por outro lado, há cursos que não contemplam esse tipo de componente curricular, com conteúdos exclusivos do Ensino Superior. É o caso da UFRR, que, além dos componentes que abordam temas da Educação Básica, há componentes que trazem intersecções entre a Matemática da Educação Básica e a Matemática do Ensino Superior, como em Estatística, cuja ementa traz:

Aplicação da estatística a resolução de problema de educação. Noções de probabilidades. Estatística Descritiva. Provas de hipóteses. Analise paramétrico e não paramétrico. Estatística Multivariada. Coeficientes de correlação. Utilizar um programa informático para o processamento dos dados (UNIVERSIDADE FEDERAL DE RORAIMA, 2011, p. 77-78).

Também a UFCG não tem componentes curriculares destinados exclusivamente à Matemática do Ensino Superior. O curso traz quatro disciplinas de conteúdo matemático; todas voltadas para a Matemática ensinada na Educação Básica: Matemática na Educação Básica I, II e III e Geometria Plana, Analítica e Espacial. Há aí, em nosso entender, uma preocupação em priorizar a Matemática que o professor irá trabalhar na escola, indo ao encontro do seguinte questionamento:

Se é para prover futuros professores com uma proficiência adequada na Matemática escolar, por que é, então, que não dedicamos diretamente uma parte muito maior dos cursos de conteúdo matemático, nas licenciaturas, à Matemática escolar? (LINS, 2005, p.119). 
Por fim, elaboramos o quadro 1, com dupla entrada, para caracterizarmos, de acordo com as análises feitas até aqui, cada componente curricular de conteúdo matemático de todos os cursos.

Categorizamos esses componentes de duas formas: (a) no que tange aos conteúdos matemáticos; e (b) sobre as relações estabelecidas em suas ementas com o contexto escolar.

Na primeira categorização, classificamos se os conteúdos referem-se: (i) à Educação Básica; (ii) ao Ensino Superior; (iii) a ambos; ou (iv) à Educação Básica ou ao Ensino Superior, dependendo do enfoque ${ }^{4}$.

$\mathrm{Na}$ segunda categorização, classificamos se as suas ementas contemplam: (i) a Matemática Escolar, como definem Moreira e David (2010); (ii) o contexto social do campo; ou (iii) exclusivamente a Matemática Acadêmica ou sua transposição didática (MOREIRA; DAVID, 2010) e aplicações que não sejam ao contexto social do campo ${ }^{5}$.

\begin{tabular}{|c|c|c|c|c|}
\hline $\begin{array}{l}\text { Conteúdos a que } \\
\text { se referem / O } \\
\text { que as ementas } \\
\text { contemplam }\end{array}$ & Educação Básica & Ensino Superior & $\begin{array}{c}\text { Educação Básica e } \\
\text { Ensino Superior }\end{array}$ & $\begin{array}{l}\text { Educação Básica } \\
\text { ou Ensino } \\
\text { Superior, } \\
\text { dependendo do } \\
\text { enfoque }\end{array}$ \\
\hline $\begin{array}{l}\text { Matemática } \\
\text { Escolar }\end{array}$ & $\begin{array}{c}\text { IFFarroupilha (1): } \\
\text { Estatística Básica. } \\
\text { UFCG (2): } \\
\text { Matemática na } \\
\text { Educação Básica I } \\
\text { e III. } \\
\text { UFPA (2): } \\
\text { Matemática Básica } \\
\text { I e II. }\end{array}$ & & & $\begin{array}{c}\text { UFCG (1): } \\
\text { Geometria Plana, } \\
\text { Analítica e } \\
\text { Espacial. }\end{array}$ \\
\hline $\begin{array}{l}\text { Contexto social } \\
\text { do campo }\end{array}$ & $\begin{array}{c}\text { UFRB (4): } \\
\text { Matemática na } \\
\text { Educação Básica I, } \\
\text { III e IV, Elementos } \\
\text { de Geometria Plana } \\
\text { e Espacial. } \\
\text { UNICENTRO (2): } \\
\text { Matemática } \\
\text { aplicada à vida no } \\
\text { campo, Geometria } \\
\text { aplicada à vida no } \\
\text { campo II. } \\
\text { UNIOESTE (1): } \\
\text { Geometria, Ótica e } \\
\text { a percepção do } \\
\text { espaço. }\end{array}$ & $\begin{array}{c}\text { UFPA (1): } \\
\text { Geometria Plana e } \\
\text { o Espaço Agrário. } \\
\text { UFRB (3): Cálculo } \\
\text { A, B e C. } \\
\text { UNIOESTE (3): } \\
\text { Cálculo Diferencial } \\
\text { e a vida no campo, } \\
\text { Cálculo Integral e a } \\
\text { vida no campo, } \\
\text { Estatística e a vida } \\
\text { no campo. }\end{array}$ & $\begin{array}{c}\text { UFRB (3): } \\
\text { Combinatória, } \\
\text { Estatística e } \\
\text { Probabilidade, } \\
\text { Geometria } \\
\text { Analítica, } \\
\text { Matemática } \\
\text { Financeira. } \\
\text { UNICENTRO (2): } \\
\text { Cálculo diferencial } \\
\text { e integral aplicado } \\
\text { à vida no campo, } \\
\text { Estatística aplicada } \\
\text { à vida no campo. } \\
\text { UNIOESTE (1): } \\
\text { Educação } \\
\text { Financeira. }\end{array}$ & $\begin{array}{l}\text { UFRR (1): } \\
\text { Geometria. } \\
\text { UNICENTRO } \\
\text { (1): Geometria } \\
\text { aplicada à vida } \\
\text { no campo I. }\end{array}$ \\
\hline
\end{tabular}

\footnotetext{
${ }^{4}$ Essas categorias são mutuamente excludentes, isto é, um item não consta em mais de uma delas e, também, não há componente que não foi classificado em uma delas.

${ }^{5}$ Essas categorias não são mutuamente excludentes. Há, portanto, a possibilidade de um componente curricular pertencer a mais de uma delas. Todos os componentes, porém, fazem parte de, pelo menos, uma categoria.
} 


\begin{tabular}{|c|c|c|c|c|}
\hline $\begin{array}{c}\text { Matemática } \\
\text { Acadêmica ou } \\
\text { sua transposição } \\
\text { didática e } \\
\text { aplicações que } \\
\text { não sejam ao } \\
\text { contexto social } \\
\text { do campo }\end{array}$ & $\begin{array}{l}\text { IFFarroupilha (5): } \\
\text { Matemática Básica } \\
\text { I, II e III, } \\
\text { Geometria Plana e } \\
\text { Geometria } \\
\text { Espacial, } \\
\text { Geometria } \\
\text { Analítica. } \\
\text { UFCG (1): } \\
\text { Matemática na } \\
\text { Educação Básica } \\
\text { II. } \\
\text { UFPA (1): } \\
\text { Introdução à } \\
\text { Probabilidade } \\
\text { Estatística. } \\
\text { UFRB (1): } \\
\text { Matemática na } \\
\text { Educação Básica } \\
\text { II. } \\
\text { UFRR (2): } \\
\text { Matemática Básica, } \\
\text { Álgebra. } \\
\text { UNICENTRO (1): } \\
\text { Fundamentos de } \\
\text { Matemática. } \\
\text { UTFPR (1): } \\
\text { Tópicos de } \\
\text { Matemática. }\end{array}$ & $\begin{array}{l}\text { IFFarroupilha (6): } \\
\text { Cálculo I, II e III, } \\
\text { Análise Real, } \\
\text { Cálculo Numérico, } \\
\text { Equações } \\
\text { Diferenciais } \\
\text { Ordinárias. } \\
\text { UFPA (8): Álgebra } \\
\text { I, Análise Real } \\
\text { Elementar, Cálculo } \\
\text { I, II, III e IV, } \\
\text { Cálculo Numérico, } \\
\text { Lógica Aplicada à } \\
\text { Matemática. } \\
\text { UFRB (1): Álgebra } \\
\text { Linear. } \\
\text { UTFPR (4): } \\
\text { Fundamentos de } \\
\text { Matemática } \\
\text { Elementar, Cálculo } \\
\text { Diferencial } \\
\text { Integral, Equações } \\
\text { Diferenciais } \\
\text { Aplicadas, } \\
\text { Introdução à } \\
\text { Análise Real. }\end{array}$ & $\begin{array}{l}\text { IFFarroupilha (2): } \\
\text { Álgebra Linear, } \\
\text { Matemática } \\
\text { Financeira. } \\
\text { UFPA (3): Álgebra } \\
\text { Linear Elementar, } \\
\text { Construções } \\
\text { Geométricas, } \\
\text { Geometria } \\
\text { Analítica. } \\
\text { UFRR (1): } \\
\text { Estatística. } \\
\text { UTFPR (3): } \\
\text { Álgebra Linear e } \\
\text { Geometria } \\
\text { Analítica B, } \\
\text { Funções Reais de } \\
\text { uma variável real, } \\
\text { Educação } \\
\text { Financeira. }\end{array}$ & $\begin{array}{l}\text { IFFarroupilha (1): } \\
\text { Álgebra. } \\
\text { UFPA (1): Teoria } \\
\text { dos Números. } \\
\text { UFRB (1): } \\
\text { Álgebra. } \\
\text { UTFPR (1): } \\
\text { Tópicos de } \\
\text { Geometria } \\
\text { Elementar. }\end{array}$ \\
\hline
\end{tabular}

Quadro 1 - Caracterização dos componentes curriculares de conteúdo matemático

Fonte: produzido pelos autores (2015)

\section{Considerações finais}

Nesta pesquisa, buscamos analisar o lugar da Matemática em cursos de Licenciatura em Educação do Campo com habilitação em Matemática, a partir de seus documentos oficiais. Para isso, pautados na Análise Textual Discursiva (MORAES; GALIAZZI, 2011) como referencial metodológico, olhamos três itens do projeto político-pedagógico de oito cursos em andamento: os objetivos do curso, o perfil esperado do egresso e as ementas dos componentes curriculares. Entendemos que um curso tão específico - como é o caso - deve levar em conta o perfil esperado do egresso ao determinar o lugar da Matemática em sua estrutura curricular.

Para tentar localizar a Matemática nesses cursos de formação, focamos em dois aspectos: como tem sido o equacionamento dos papéis da Matemática Científica e da Matemática Escolar, no sentido de Moreira e David (2010); e qual perspectiva, dentre aquelas destacadas em Fiorentini e Oliveira (2013), tem sido adotada por eles. 
No que se refere ao equacionamento dos papéis da Matemática Científica e da Matemática Escolar, percebemos a predominância da primeira, com pouca Matemática Escolar, isto é, pouco espaço para uma Matemática “[...] que se expressa, em última instância, nas relações com as condições colocadas pelo trabalho educativo na própria sala de aula [...]” (MOREIRA; DAVID, 2010, p. 46). Apenas quatro componentes curriculares - uma no IFFarroupilha, duas na UFCG e duas na UFPA - trazem indícios para uma Matemática Escolar em suas ementas.

Com relação a qual perspectiva na formação do professor de Matemática tem sido adotada nesses cursos, dentre as três destacadas por Fiorentini e Oliveira (2012), consideramos que predominam as duas primeiras, em que o papel da Matemática é central e que, na maioria dos casos, as disciplinas de conteúdo matemático vêm dissociadas do contexto social, das disciplinas didático-pedagógicas e da prática do professor. São 44 componentes curriculares com essas características, no total.

O contexto social camponês é trazido em grande parte dos projetos de curso, nos itens objetivo e perfil do egresso, sendo que muitos deles deixam explícita a importância em articular a formação do professor com os saberes próprios do campo. Porém, no que se refere às ementas dos componentes curriculares, esse aspecto é menos evidente. Cinco instituições UFRB, UFPA, UFRR, UNICENTRO e UNIOESTE - têm disciplinas com indicações dessa associação, levando em conta as práticas sociais dos futuros professores em um contexto específico. Curiosamente, não são necessariamente as mesmas instituições que trazem isso em seus objetivos e perfil do egresso.

É importante ressaltar que há componentes curriculares que deixam clara qual relação estabelecida entre o conteúdo matemático e o contexto camponês - como é o caso de Geometria Plana e Espaço Agrário, da UFPA, e Educação Financeira, da UNIOESTE. Há, em contrapartida, componentes que apenas indicam que essa relação deve ocorrer - seja com itens como "Aplicações contextualizadas na realidade do campo" em suas ementas ou com seus nomes, como é o caso de Cálculo Diferencial e a vida no campo.

Os componentes curriculares, quantitativamente, trazem, de maneira equivalente, conteúdos matemáticos da Educação Básica e do Ensino Superior, sendo 24 disciplinas que tratam exclusivamente dos primeiros e 26 exclusivamente dos segundos; porém, alguns cursos privilegiam uma ou outra - como é o caso da UFPA, que tem nove componentes focados na Matemática do Ensino Superior e apenas três na Matemática da Educação Básica, e da UFCG, que tem todos os seus quatro componentes tratando temas da Matemática da Educação Básica, dos quais três tratam dela exclusivamente. 
Para concluir, reafirmamos que o projeto político-pedagógico é um documento que pode orientar as práticas pedagógicas do professor, porém elas dependem fortemente dos próprios professores que atuam no curso, de suas visões de mundo, de sua relação com o conhecimento e de sua forma de lidar com as situações de aula. Isso significa que mesmo que um componente curricular não traga em sua ementa articulações com a prática social do educador matemático, o professor formador pode fazê-las; ou, ao contrário, uma disciplina pode estabelecer em sua ementa uma relação entre o conhecimento matemático e o contexto social, mas o professor que a leciona pode ignorá-la. Por isso, entendemos a necessidade de se dar continuidade nesta pesquisa em outras direções, como, por exemplo, o acompanhamento de aulas nesses cursos para verificar, na prática, como se dá essa relação. Também, seria complementar a esta pesquisa realizar uma análise das bibliografias básica e complementar dos componentes curriculares desses cursos, a fim de identificar se há ou não bibliografia que relaciona conteúdos matemáticos aos saberes do campo e, se houver, de que modo.

\section{Referências}

BARBOSA, L. N. S. C. Entendimentos a respeito da matemática na educação do campo: questões sobre currículo. 2014. 234 f. Tese (Doutorado em Educação Matemática) - Universidade Estadual Paulista "Júlio de Mesquita Filho", Rio Claro, 2014.

BRASIL. Ministério da Educação. Secretaria de Educação Continuada, Alfabetização e Diversidade. Edital de Convocação nº 09, de 29 de abril de 2009. Diário Oficial da União, Brasília, 30 abr. 2009. Seção 3, p.57-59.

BRASIl. Ministério da Educação. Secretaria de Educação Continuada, Alfabetização, Diversidade e Inclusão. Edital de Chamada Pública no 2, de 31 de agosto de 2012. Diário Oficial da União, Brasília, 5 set. 2012. Seção 3, p.59-60.

ELIAS, H. R.; BARBOSA, L. N. S. C.; SAVIOLI, A. M. P. D. Matemática elementar e avançada em livros didáticos: o conceito dos números naturais. In: CONFERÊNCIA INTERAMERICANA DE EDUCAÇÃO MATEMÁTICA, 13., 2011, Recife. Anais... Recife, 2011, p. 1-11. Disponível em: 〈http://www.gente.eti.br/lematec/CDS/XIIICIAEM/artigos/1450.pdf>. Acesso em: 7 fev. 2015.

FIORENTINI, D. A Formação matemática e didático-pedagógica nas disciplinas da Licenciatura em Matemática. Revista de Educação, Campinas, v. 1, n. 18, p. 107-115, 2005.

FIORENTINI, D.; OLIVEIRA, A. T. C. C. O lugar das Matemáticas na Licenciatura em Matemática: que matemáticas e práticas formativas? Bolema, Rio Claro, v. 27, n. 47, p. 917-938, 2013.

INSTITUTO FEDERAL FARROUPILHA. Projeto pedagógico do curso Licenciatura em Educação do Campo. Jaguari, 2012. Disponível em: <http://www.ja.iffarroupilha.edu .br/site/midias/arquivos/2013719141850268ppc_jaguari__licenciatura_do_campo.pdf $>$. Acesso em: 25 ago. 2013. 
INSTITUTO NACIONAL DE ESTUDOS E PESQUISAS EDUCACIONAIS ANÍSIO TEIXEIRA. Panorama da educação do campo. Brasília: Instituto Nacional de Estudos e Pesquisas Educacionais Anísio Teixeira, 2007.

LEITE, S. C. Escola rural: urbanização e políticas educacionais. São Paulo: Cortez, 1999.

LINS, R. C. A formação pedagógica nas disciplinas de conteúdo matemático nas licenciaturas em Matemática. Revista de Educação, Campinas, v. 1, n. 18, p. 117-123, 2005.

MORAES, R.; GALIAZZI, M. C. Análise Textual Discursiva. Ijuí: Editora Unijuí, 2011.

MOREIRA, P. C.; DAVID, M. M. M. S. A formação matemática do professor: licenciatura e prática docente. Belo Horizonte: Autêntica, 2010.

MUNARIM, A. Movimento Nacional de Educação do Campo: uma trajetória em construção. In: REUNIÃO ANUAL DA ASSOCIAÇÃO NACIONAL DE PÓS-GRADUAÇÃO E PESQUISA EM EDUCAÇÃO, 31., 2008, Caxambu. Anais... Caxambu, 2008, p.1-17. Disponível em: <http://31 reuniao.anped.org.br/1 trabalho/GT03-4244--Int.pdf>. Acesso em: 28 out. 2013.

UNIVERSIDADE ESTADUAL DO CENTRO-OESTE. Projeto Pedagógico/Curso Licenciatura em Educação do Campo. Guarapuava, 2009. Disponível em: <http://sites.unicentro.br/wp/educacao docampo/files/2012/09/PropostaLicenciaturaUnicentro19out2009.pdf >. Acesso em: 26 ago. 2013.

UNIVERSIDADE ESTADUAL DO OESTE DO PARANÁ. Aprova o projeto político-pedagógico do curso de Licenciatura em Educação do Campo, do campus de Cascavel, para os acadêmicos do curso com matrícula ativa. Resolução no 020/2013-CEPE, de 21 de março de 2013. Cascavel, 2013.

UNIVERSIDADE FEDERAL DE CAMPINA GRANDE. Projeto pedagógico do curso de Licenciatura em Educação do Campo. Sumé, 2012. Disponível em: <http://www.cdsa.ufcg. edu.br/portal/outras_paginas/documentos/ppc/ppc_educacao_do_campo.pdf $>$. Acesso em: 26 ago. 2013.

UNIVERSIDADE FEDERAL DE RORAIMA. Curso de Licenciatura em Educação do Campo. Projeto político-pedagógico - PPP. Boa Vista, 2011. Disponível em: <http://ufrr.br/leducarr/index .php?option=com phocadownload $\&$ view $=$ category $\&$ download $=46: p p p \& \mathrm{id}=2:$ resgimento $\&$ Itemid $=20$ 1>. Acesso em: 26 ago. 2013.

UNIVERSIDADE FEDERAL DO PARÁ. Projeto Político-Pedagógico: curso de Licenciatura Plena em Educação do Campo. Abaetetuba, 2009. Disponível em: <http://www.ufpa.br/cubt/publicacoes /documento/facet/educdocampo/ppp.pdf >. Acesso em: 25 ago. 2013.

UNIVERSIDADE FEDERAL DO RECÔNCAVO DA BAHIA. Projeto Pedagógico do Curso de Licenciatura em Educação do Campo com Habilitações em Ciências da Natureza e Matemática. Feira de Santana, 2013. Disponível em: 〈http://www.ufrb.edu.br/portal/component/phocadownload /category/2documentos?download=45:projeto-de-criacao-do-curso-de-educacao-do-campo-em-feirade-santana> Acesso em: 29 dez. 2013.

UNIVERSIDADE TECNOLÓGICA FEDERAL DO PARANÁ. Projeto de Abertura do Curso de Licenciatura em Educação do Campo. Dois Vizinhos, 2010. Disponível em: <http://www.utfpr .edu.br/doisvizinhos/cursos/licenciaturas/Ofertados-neste-Campus/educacao-no-campo/documento s/ProjetoPROCAMPOversaoFINAL220910.pdf>. Acesso em: 30 dez. 2013.

Submetido em Abril de 2015. Aprovado em Outubro de 2015. 